\title{
Dr. Hirschhausen meets Dr. House
}

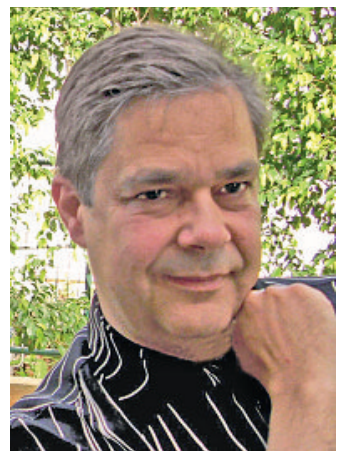

Eberhard Wolff
Kennen Sie das «Hirschhausen-Syndrom»? Nein? Macht nichts! Selbst Google kennt allenfalls das «Münchhausen-Syndrom». Aber so, wie es aussieht, könnte sich das bald ändern. Worum es dabei geht? Wir sprechen von «Dr. med. Eckart von Hirschhausen». Sie werden ihn als neuen Star am Kabaretthimmel und gelernten Arzt kennen. Aber: Hirschhausen ist zunächst einmal kein Syndrom, sondern ein Phänomen, vor allem, was seinen derzeitigen Erfolg betrifft. Er tourt seit Jahren durch Talkshows, «Late Nights» und Klamauksendungen. Auch hierzulande ist er von Kurt Aeschbacher und kürzlich von Viktor Giacobbo televisionär geadelt worden. Damit nicht genug, Hirschhausen besetzt mit seinen Büchern schon fast notorisch die Sachbuchbestsellerlisten. Mit seinem «Glück kommt selten allein»-Ratgeber scheint er in der Schweiz sogar seinen einheimischen Arztkollegen Remo Largo in Sachen Umsatz ausgestochen zu haben.

Das Publikum dankt ihm seine Kalauer wie «Das Stammhirn ist der Teil des Gehirns, der am Stammtisch aktiv ist» mit Hingabe. Aber Spass beiseite: Kündigen sich hier neue Wege der Gesundheitsaufklärung, ein neues Modell ärztlicher Selbstdarstellung oder ein neues Verhältnis zwischen Medizin und Öffentlichkeit an?

\section{Anti-Arzt, Autorität und Gutmensch: der Arzt, der alles kann - sogar Comedy}

Hirschhausens aktueller Bestseller ist ein lustiges Leporello zum Thema «Glück», gefüttert mit etwas Neuroscience. Der Verfasser beschreibt es vor Fachleuten als «nachhaltige Komik» und eine Art «Kognitive Verhaltenstherapie». In der Tat ist der Ansatz interessant, Lebenshilfe mit Bastelbögen, Schnappschüssen, Witzen und Aufklebern radikal alltagsattraktiv und zappingkonform zu gestalten. Doch Hirschhausens Botschaften à la «Lachen ist die beste Medizin», «Freue Dich an einfachen Dingen» oder «Geld macht nicht glücklich» tönen letzten Endes ebenso bieder und begrenzt wie Tipps aus anderen Ratgebern. Sein «Glückskeksbastelbogen» nähert sich denn auch schnell einmal dem Niveau der Glückskeksweisheiten im Chinarestaurant.

Hirschhausen nimmt auch die Absurditäten der Medizin, z. B. Hierarchien des Klinikalltags, selbstkritisch aufs Korn. Etwa so: Der Piepser macht den Arzt wichtig, aber der Chefarzt macht sich noch wichtiger, indem er keinen Piepser hat. Ist das eine Medizin, die sich selbst nicht mehr so bierernst nimmt wie auch schon, sondern entspannt über sich selbst nachdenken kann? Aber Hirschhausen witzelt auch über Analfissuren und Proktologen, und das fällt doch eher unter Spassgesellschaft oder Sauglattismus und köchelt mit alten Klischees.

Hirschhausens Medizinkritik, etwa sein Langenscheidt-Spasswörterbuch «Arzt-Deutsch/Deutsch-Arzt», will das Ärztelatein und den von ihm diagnostizierten ärztlichen Standesdünkel demaskieren. Er will zeigen, dass sich hinter einer ärztlichen Diagnose wie «essentielle, funktionelle, vegetative Dystonie» die eigentliche Botschaft «Ich weiss auch nicht, was Ihnen fehlt» verbergen kann. Andererseits: Hirschhausen versucht die Autorität des Arztimages selbst weidlich auszunutzen. Nein, nein: Wenn er mit dem Arztkoffer (oder ist es ein Hebammenköfferchen?) auftritt, im Arztkittel posiert, dann können wir dies gerne als Ironie verbuchen. Aber wenn das «Dr. med.» notorisch vor seinem Namen auf dem Cover der Bestsellerbücher, -CDs und -DVDs prangt, wenn er vor der Kamera beiläufig medizinische Fachausdrücke einfliessen lässt, ohne sie zu demaskieren, dann reitet auch Hirschhausen das patriarchalische Arztmodell im Sinne von: «Vertrauen Sie mir, ich bin Arzt, ich kenne mich aus.»

Warum erinnert mich das an «Dr. House», den virtuellen Arzt der noch viel erfolgreicheren amerikanischen Fernsehserie? Und dies, obwohl House und Hirschhausen auf den ersten Blick so gegensätzlich sind: Hier der ruppige, unangepasste House, dort der propere Lieblingsschwiegersohn Hirschhausen. Und doch sind beide Figuren auch nach dem gleichen, beim Publikum erfolgreichen Muster gestrickt: Sie sind zunächst «Antiärzte», Systemkritiker, und beide retten die Patienten am Ende doch mit einem herkömmlichen Arzt-Sein: der Arzt als Held, Autorität und Gutmensch, der alles kann - sogar Comedy.

Könnte das den Bauplan für ein «HirschhausenSyndrom» abgeben? Wir werden es sehen, vielleicht in einer kommenden Auflage des Pschyrembel, neben der «Steinlaus». Und wenn wir dann noch ein Eponym für das entspannte Nachdenken der Medizin über sich selbst suchen, würde ich doch für das «Taverna-Syndrom» plädieren.

Eberhard Wolff* 